\title{
Bioinformatic prediction of immunodominant regions in spike protein for early diagnosis of the severe acute respiratory syndrome coronavirus 2 (SARS-CoV-2)
}

\author{
Siqi Zhuang ${ }^{1}$, Lingli Tang ${ }^{1}$, Yufeng Dai ${ }^{1}$, Xiaojing Feng ${ }^{1}$, Yiyuan Fang ${ }^{1}$, Haoneng Tang ${ }^{1}$, Ping Jiang $^{1}$, Xiang Wu $^{2}$, \\ Hezhi Fang ${ }^{3}$, Hongzhi Chen ${ }^{\text {Corresp. } 4}$ \\ 1 \\ 1 Department of Laboratory Medicine, The Second Xiangya Hospital, Central South University, Changsha, Hunan, China \\ Department of Parasitology, Xiangya School of Basic Medicine, Central South University, Changsha, Hunan, China \\ ${ }^{3}$ Key Laboratory of Laboratory Medicine, Ministry of Education, Zhejiang Provincial Key Laboratory of Medical Genetics, College of Laboratory Medicine \\ and Life Sciences,, Wenzhou Medical University,, Wenzhou, Zhejiang, China \\ 4 National Clinical Research Center for Metabolic Disease, Key Laboratory of Diabetes Immunology, Ministry of Education, Metabolic Syndrome Research \\ Center, and Department of Metabolism \& Endocrinology, The Second Xiangya Hospital, Central South University, Changsha, Hunan, China \\ Corresponding Author: Hongzhi Chen \\ Email address: chenhongzhi2013@csu.edu.cn
}

Background. To contain the pandemics caused by SARS-CoV-2, early detection approaches with high accuracy and accessibility are critical. Generating an antigen-capture based detection system would be an ideal strategy complementing the current methods based on nucleic acids and antibody detection. The spike protein is found on the outside of virus particles and appropriate for antigen detection.

Methods. In this study, we utilized bioinformatics approaches to explore the immunodominant fragments on spike protein of SARS-CoV-2.

Results. The S1 subunit of spike protein was identified with higher sequence specificity. Three immunodominant fragments, Spike $\mathrm{S6}_{5-94}, \mathrm{Spike}_{199-264}$, and Spike ${ }_{577-612}$, located at the S1 subunit were finally selected via bioinformatics analysis. The glycosylation sites and high-frequency mutation sites on spike protein were circumvented in the antigen design. All the identified fragments present qualified antigenicity, hydrophilicity, and surface accessibility. A recombinant antigen with a length of 194 amino acids (aa) consisting of the selected immunodominant fragments as well as a universal Th epitope was finally constructed.

Conclusion. The recombinant peptide encoded by the construct contains multiple immunodominant epitopes, which is expected to stimulate a strong immune response in mice and generate qualified antibodies for SARS-CoV-2 detection. 


\section{Bioinformatic prediction of immunodominant regions in spike protein}

2 for early diagnosis of the severe acute respiratory syndrome

3 coronavirus 2 (SARS-CoV-2)

5 Siqi Zhuang 2 , Lingli Tang 2 , Yufeng Dai ${ }^{2}$, Xiaojing Feng 2 , Yiyuan Fang ${ }^{2}$, Haoneng Tang 2 , Ping

6 Jiang $^{2}$, Xiang Wu ${ }^{3}$, Hezhi Fang ${ }^{4}$, Hongzhi Chen ${ }^{1}$

8 1. National Clinical Research Center for Metabolic Disease, Key Laboratory of Diabetes

9 Immunology, Ministry of Education, Metabolic Syndrome Research Center, and Department of

10 Metabolism \& Endocrinology, The Second Xiangya Hospital, Central South University,

11 Changsha, Hunan 410011, China

12 2. Department of Laboratory Medicine, The Second Xiangya Hospital, Central South University,

13 Changsha, Hunan 410011, China.

14 3. Department of Parasitology, Xiangya School of Basic Medicine, Central South University,

15 Changsha, Hunan 410013, China

4. Key Laboratory of Laboratory Medicine, Ministry of Education, Zhejiang Provincial Key

17 Laboratory of Medical Genetics, College of Laboratory Medicine and Life Sciences, Wenzhou

Medical University, Wenzhou, Zhejiang 325035, China

20 Corresponding author:

21 Hongzhi Chen ${ }^{1}$ 
E-mail address: chenhongzhi2013@csu.edu.cn

Abstract

Background. To contain the pandemics caused by SARS-CoV-2, early detection approaches with high accuracy and accessibility are critical. Generating an antigen-capture based detection system would be an ideal strategy complementing the current methods based on nucleic acids and antibody detection. The spike protein is found on the outside of virus particles and appropriate for antigen detection.

Methods. In this study, we utilized bioinformatics approaches to explore the immunodominant fragments on spike protein of SARS-CoV-2.

Results. The S1 subunit of spike protein was identified with higher sequence specificity. Three immunodominant fragments, Spike $_{56-94}$, Spike $_{199-264}$, and Spike ${ }_{577-612}$, located at the S1 subunit were finally selected via bioinformatics analysis. The glycosylation sites and high-frequency mutation sites on spike protein were circumvented in the antigen design. All the identified fragments present qualified antigenicity, hydrophilicity, and surface accessibility. A recombinant antigen with a length of 194 amino acids (aa) consisting of the selected immunodominant fragments as well as a universal Th epitope was finally constructed.

Conclusion. The recombinant peptide encoded by the construct contains multiple immunodominant epitopes, which is expected to stimulate a strong immune response in mice and 41 generate qualified antibodies for SARS-CoV-2 detection. 


\section{Introduction}

43

44

The severe acute respiratory syndrome coronavirus 2 (SARS-CoV-2) is highly contagious and has caused more than one hundred million infection cases and over 2.4 million deaths (https://www.who.int/, as of February 15, 2021), posing a huge economic and social burden internationally (Lan et al. 2020; Shang et al. 2020). The reports of SARS-CoV-2 reinfection cases suggest that stronger international efforts are required to prevent COVID-19 re-emergence in the future(Zhan et al. 2020). Nevertheless, the possibility of SARS-CoV-2 becoming a seasonal epidemic cannot be excluded (Shaman \& Galanti 2020). Even worse, the large number of asymptomatic infections greatly increase the difficulties of epidemic control(Rothe et al. 2020). At present, no specific drugs have been developed for SARS-CoV-2, and the effectiveness of the vaccines on the market still needs time to be evaluated. Therefore, early detection and isolation of infected people are still indispensable means to control the spread of the epidemic, which requires accurate, early, economical, and easy-to-operate diagnostic methods(Yan et al. 2020).

The real-time reverse transcriptase-polymerase chain reaction(RT-PCR) and antibodycapture serological tests are currently the main diagnostic methods for SARS-CoV-2 (Ishige et al. 2020). As the golden standard, RT-PCR is highly reliable (Bustin \& Nolan 2020; Padoan et al. 2020). However, the implementation costs and relatively cumbersome operation problems make it a big challenge for large population screening(Thabet et al. 2020). The antibody-capture serological test is convenient, but seroconversion generally occurs in the second or third week of illness. Therefore, it is not ideal for the early diagnosis of infection (Hachim et al. 2020; Liu et 
63

64

al. 2020; Tang et al. 2020). The antigen-capture test is an alternative diagnostic method that relies on the immunodetection of viral antigens in clinical samples. Accordingly, this method could be applied for the detection of early infection no matter if the patient was asymptomatic or not (Ohnishi 2008). Compared with RT-PCR based detection method, it is relatively inexpensive and can be used at the point-of-care.

Rapid viral antigen detection has been successfully used for diagnosing respiratory viruses such as influenza and respiratory syncytial viruses (Cazares et al. 2020; Ji et al. 2011; Ohnishi et al. 2005; Ohnishi et al. 2012; Qiu et al. 2005). The sensitivity and specificity of the antigencapture detection system depend highly on the antigen employed to generate antibodies (Ohnishi et al. 2012). The spike protein is one of the structural proteins of SARS-CoV-2, with the majority located on the outside surface of the viral particles (Fehr \& Perlman 2015; Kumar et al. 2020; Woo et al. 2005). It has a 76.4\% homology with the spike protein of SARS-CoV. Sunwoo's study showed that the bi-specific spike protein derived monoclonal antibody system exhibited excellent sensitivity in SARS-CoV detection (Sunwoo et al. 2013). The virus infection is initiated by the interaction of spike protein receptor-binding domain (RBD) and angiotensinconverting enzyme 2 (ACE2) on host cells. It is widely accepted that the spike protein is one of the earliest antigenic proteins recognized by the host immune system (Callebaut et al. 1996; Chen et al. 2020c; Gomez et al. 1998; Lu et al. 2004; Sanchez et al. 1999). Nevertheless, the difficulties of using spike protein as an antigen are also obvious. Firstly, it is not easy to express and purify the full-length spike protein (Tan et al. 2004). Besides, the spike protein is highly glycosylated (Kumar et al. 2020) and prone to mutation(Wang et al. 2020a), which may 
84

85

86

87

counteract the sensitivity of antigen-capture based detection method. Hence, it is critical to truncating the glycosylation and mutation sites on spike protein as much as possible in antigen design (Meyer et al. 2014; Tan et al. 2004). A study using the truncated spike protein to detect SARS-CoV achieved a diagnostic sensitivity of $>99 \%$ and a specificity of $100 \%$ (Mu et al. 2008), which suggests that the truncated spike protein of SARS-CoV-2 could also be an appropriate candidate for the early diagnostic testing and screening of SARS-CoV-2. In this study, we analyzed the spike protein via bioinformatics tools to obtain immunodominant fragments. The predicted sequences were joined together as a novel antigen for the immunization of mice and antibody production. Epitopes information presented by this work may aid in developing a promising antigen-capture based detection system in pandemic surveillance and containment.

\section{Method}

\section{Data retrieval and sequence alignment}

Multiple bioinformatics analysis tools were used in this study, and the flowchart is depicted in Fig. 1. Coronaviruses had four genera composed of alpha-, beta-, gamma- and deltacoronaviruses. Among them, alpha- and beta- genera could infect humans. Seven betacoronaviruses are known to infect humans (HCoV-229E, HCoV-OC43, HCoV-NL63, HCoVHKU1, SARS-CoV, MERS-CoV, and SARS-CoV-2) (Kin et al. 2015; Su et al. 2016). We utilized the NCBI database to obtain the sequences of these human-related coronaviruses spike proteins, of which accession numbers were presented in Fig. 2A. The Clustal Omega Server- 
105

106

107

108

109

110

111

112

113

114

115

116

117

118

119

120

121

122

123

124

125

Multiple Sequence Alignment was used to analyze the sequence similarity. The analysis of the

phylogenetic tree was calculated by the same server. In this study, we set parameters of Clustal

Omega as default (Sievers et al. 2011). Additionally, we conducted the EMBOSS Needle Server-

Pairwise Sequence Alignment(Needleman \& Wunsch 1970) to compare the whole sequence and several major domains between SARS-CoV-2 and SARS-CoV to find out the specific genomic regions on SARS-CoV-2.

\section{Linear B-cell epitope prediction}

Linear B-cell epitopes of the SARS-CoV-2 spike protein were calculated by ABCpred and

Bepipred v2.0 servers. For ABCpred, we set a threshold of 0.8 to achieve a specificity of $95.50 \%$ and an accuracy of $65.37 \%$ for prediction. The window length was set to 16 (the default window length) in this study (Saha \& Raghava 2006). The BepiPred v2.0 combines a hidden Markov model and a propensity scale method. The score threshold for the BepiPred v2.0 was set to 0.5 (the default value) to obtain a specificity of $57.16 \%$ and a sensitivity of $58.56 \%$ (Jespersen et al. 2017). The residues with scores above 0.5 were predicted to be part of an epitope.

\section{T-cell epitope prediction}

The free online service TepiTool server, integrated into the Immune Epitope Database (IEDB), was used to forecast epitopes binding to mice MHC molecules(Paul et al. 2016). Alleles including H-2-Db, H-2-Dd, H-2-Kb, H-2-Kd, H-2-Kk, and H-2-Ld were selected for MHC-I binding epitopes analysis. We checked the "IEDB recommended" option during computation and 
126

127

128

129

130

131

132

133

134

135

136

137

138

139

140

141

142

143

144

145

146

retained sequences with predicted consensus percentile rank $\leq 1$ as predicted epitope(Trolle et al.

2015). For MHC-II binding epitopes, alleles including H2-IAb, H2-IAd, and H2-IEd were

selected for analysis. As the same as MHC-I binding computation, we chose the "IEDB

recommended" option, and peptides with predicted consensus percentile rank $\leq 10$ were

identified as potential epitopes(Wang et al. 2010; Zhang et al. 2012).

\section{Profiling and evaluation of selected fragments}

The secondary structure of the SARS-CoV-2 spike protein (PDB ID: 6VSB chain B) was

calculated by the PyMOL molecular graphics system using the SSP algorithm. PyMOL

(http://www.pymol.org) is a python-based tool, which is widely used for visualization of

macromolecules, such as SARS-CoV-2 spike protein in the current study (Yuan et al. 2016).

Vaxijen2.0 server was utilized to analyze the antigenicity of epitopes and selected fragments. A

default threshold of 0.4 was set and the prediction accuracy is between $70 \%$ and $89 \%$

(Doytchinova \& Flower 2007). The hydrophilicity of the selected fragment was analyzed by the

online server ProtScale (Wilkins et al. 1999). Surface accessibility of predicted fragments was

evaluated by NetsurfP, an online server calculating the surface accessibility and secondary

structure of amino acid sequence (Petersen et al. 2009). Critical features such as allergenicity and

toxicity were evaluated by online server AllerTOP v2.0 (Dimitrov et al. 2014) and ToxinPred

(Gupta et al. 2013). In addition, we utilized IEDB (www.iedb.org) to search the selected

fragments and epitopes to clarify whether these peptides have been experimentally verified(Vita

et al. 2019). Protein sequence BLAST was performed to evaluate the possibility of cross-

Peer) reviewing PDF | (2020:12:56038:1:2:NEW 1 Mar 2021) 
147 reactivity with other mouse protein sequences(Altschul et al. 1997).

148

149

150

151

152

153

154

155

156

157

158

159

160

161

162

163

164

165

166

167

\section{Results}

\section{Sequence alignment of spike protein in different coronaviruses}

We performed sequence alignment to determine the evolutionary relationships between

SARS-CoV-2 and other beta-coronaviruses that could infect humans. According to the results of sequence alignment (Fig. 2A, Fig. 2B), SARS-CoV is the closest virus to SARS-CoV-2 among the seven HCoVs, exhibiting a 77.46\% sequence identity. To better understand the divergence of spike protein sequences between SARS-CoV-2 and SARS-CoV, we further analyzed the sequences of main domains. Results showed that the S2 subunit was the most conserved domain with a 90.0\% identity. RBM and NTD domains, which were located in the S1 subunit, exhibited 49.3\% and 50.0\% identity respectively (Fig. 2C, Fig. 2D). Hence, we chose the S1 subunit (amino acid 1-685) for the subsequent bioinformatics analysis given their high specificity.

\section{Linear B-cell epitope prediction of S1 subunit in SARS-CoV-2 spike} protein

The B-cell epitope is a surface accessible cluster of amino acids, which could be recognized by secreted antibodies or B-cell receptors and elicit humoral immune response (Getzoff et al. 1988). The immunodominant fragments should contain high-quality linear B-cell epitopes to stimulate antibody production effectively. The sequence of the SARS-CoV-2 S1 subunit was evaluated via ABCpred and BepiPred v2.0. A total of 31 peptides were identified by 
168

169

170

171

172

173

174

175

176

177

178

179

180

181

182

183

184

185

186

187

188

the ABCpred algorithm (Table S1). For the Bepipred v2.0 server, 14 epitopes were forecasted

(Table S2). After antigenicity evaluation, 19 and 9 potential linear B-cell epitopes predicted by

the ABCpred server and BepiPred v2.0 server were obtained respectively (Table 1). The peptides

predicted by both bioinformatics programs are more likely to be an epitope recognized in vivo.

After mapping the positions of peptides identified by these servers, 3 regions containing

predicted epitopes were obtained. These regions could be preliminarily considered as candidates

for immunodominant fragments (Fig.3, Table 2).

\section{Murine T-cell epitope prediction of S1 subunit in SARS-CoV-2 spike}

protein

Though B cells are responsible for producing antibodies, humoral immunity is heavily dependent on the activation of T cells (Cho et al. 2019a). Helper T cells (Th) recognize antigen

peptides presented by MHC-II molecules and facilitate the humoral immune response (Cho et al.

2019b; Mahon et al. 1995). During humoral immune responses, antigen-activated T cells could

provide help in many aspects including directing antibody class switching and guiding the

differentiation of antibody-secreting plasma cells as well as the properties of the B-cell antigen

receptor(Cho et al. 2019a; Paus et al. 2006; Shulman et al. 2014). Therefore, the

immunodominant fragments containing T-cell epitopes could offer essential help to powerful

antibody production. The S1 subunit was selected for the prediction of T-cell epitopes. We

utilized the TepiTool server to forecast MHC-I and MHC-II binding epitopes. A total of 35

MHC-I binding epitopes was predicted (Table S3), and 27 peptides were identified as MHC-II

Peer] reviewing PDF | (2020:12:56038:1:2:NEW 1 Mar 2021) 
189

190

191

192

193

194

195

196

197

198

199

200

201

202

203

204

205

206

207

208

209

binding epitopes (Table S4). The antigenicity of these peptides was calculated via Vaxijen 2.0

server (Table 3). Combined with the MHC-II epitopes prediction results, the candidate

immunodominant fragments were adjusted (Fig.4). Compared with the preliminary candidate

immunodominant fragments screened according to the linear B-cell epitope prediction, we added

the Spike $_{14-34}$ fragment into consideration because it contains a linear B epitope and an MHC-II

binding epitope, both of which had high antigenicity scores (Table 4).

\section{Immunodominant fragments refinement according to the}

\section{glycosylation site distribution, mutation site distribution, and}

\section{secondary structure}

A profile of 24 glycosylation sites of SARS-CoV-2 spike protein has been reported

(Shajahan et al. 2020). Since glycans could hinder the recognition of antigens by shielding the

residues (Walls et al. 2019), protein glycosylation would affect the performance of antigen

detection. Thus, glycosylation sites should be circumvented when selecting the immunodominant

fragments. According to the study of Asif Shajahan et al, 15 glycosylation sites were located in

the S1 subunit of the spike protein(Shajahan et al. 2020). Hence, the fragments in this study were

adjusted to Spike $_{14-34}$, Spike $_{49-101}$, Spike $_{199-261}$, and Spike $_{583-620}$. To retain antigenicity of the

epitopes, the final identified fragments only contained 3 glycosylation sites which should have a

minimum effect on antigen recognition.

Rapid transmission of COVID-19 provides the SARS-CoV-2 with substantial opportunities

for natural selection and mutations. To ensure the stability of the detection method, the

Peer] reviewing PDF | (2020:12:56038:1:2:NEW 1 Mar 2021) 
210

211

212

213

214

215

216

217

218

219

220

221

222

223

224

225

226

227

228

229

230

immunodominant fragments were modified to avoid high-frequency mutation sites(Wang et al.

2020b). Spike ${ }_{14-34}$ were excluded for containing four high-frequency mutation sites. Fragment

Spike $_{49-101}$ was adjusted to Spike ${ }_{56-92}$, and fragment Spike $_{583-620}$ was adjusted to Spike 583-609. By

adjusting the fragments, we avoided in a total of 8 high-frequency mutation sites (L5F, L18F,

T29I, R21K/T, H49Y, L54F, S98F, D614G). The mainly mutant sites on the recent emergent

highly infectious variants (including B.1.1.7, B.1.351, and P.1), such as N501Y, D614G, E484K,

Y144del, K417N, and A570D were also not included in our fragments. The adjusted fragments

contain none of the above high-frequency mutation sites, which might avoid the impact of

mutations on detection performance and improve the detection efficiency in the future(Li et al.

2020; Tegally et al. 2020).

The PyMOL was used to present the secondary structure of the spike protein (PDB ID:

6VSB ) (Fig. S1). To keep the integrity of the secondary structure of the selected fragments, we extended the $\mathrm{N}$ - and $\mathrm{C}$ - ends with $2 \sim 5$ residues, and the immunodominant fragments were finally adjusted to Spike $_{56-94}$, Spike $_{199-264}$, and Spike ${ }_{577-612 .}$ The epitopes and potential glycosylation sites contained in the selected immunodominant fragments were displayed in Fig. 5.

\section{Profiling, evaluation, and visualization of selected immunodominant}

\section{fragments}

To further evaluate the antibody binding potentiality of these antigenic regions, the key

features of the selected fragments such as antigenicity, hydrophilicity, surface accessibility, toxicity, and allergenicity were analyzed and presented (Table 5). The hydrophilicity and surface 
231 accessibility of the spike protein subunit 1 were calculated. The selected fragments of interest

232 were submitted for computation of antigenicity, toxicity, and allergenicity. Three fragments

233 presented relatively moderate hydrophilicity and surface accessibility. The proportion of

234 hydrophilic amino acids in the selected fragments Spike $_{56-94}$, Spike $_{199-264}$, Spike $_{577-612}$ are

$48.72 \%, 45.45 \%, 33.33 \%$ respectively. The surface accessibility of these fragments calculated by the online server was shown in Table 5.

The toxicity of the selected fragments was examined and no fragment was predicted to be toxic. The allergenicity was assessed and only fragment Spike $_{577-612}$ was predicted to be a probable allergen. Attention should be paid to monitor potential allergic reactions when injecting the recombinant protein into mice. And the selected fragments were presented as the sphere in the trimer structure (Fig. 6). Next, we scanned the selected fragments utilizing the IEDB database to determine whether they were experimentally tested. The results showed that Spike $_{200-}$ ${ }_{215}($ IEDB ID: 1330367) and Spike $238-252$ (IEDB ID: 1329417) were identified experimentally as

HLA class II epitope in SARS-CoV-2. Spike84-92 (IEDB ID: 1321049) and Spike202-210 (IEDB ID:

1319559) have been experimentally proved as HLA-B epitopes. (Table S5). These findings enhanced the credibility of the current in silico analysis. The fragments identified would have a strong capacity in stimulating powerful antibody production.

\section{Immunodominant fragments based recombinant antigen design}

Three immunodominant fragments embody several linear B-cell epitopes, MHC-I binding, 
252

253

254

255

256

257

258

259

260

261

262

263

264

265

266

267

268

269

270

271

272

epitope [PADRE(AKFVAAWTLKAAA)] was added into the construction aiming to boost helper T cell activity (Alexander et al. 2000; Ghaffari-Nazari et al. 2015). (GGGGS) is a wildly used flexible linker with the function of segmenting protein fragments, maintaining protein conformation, preserving biological activity, and promoting protein expression (Chen et al. 2013). Finally, we combined the fragments and a PADRE epitope by linker peptide (GGGGS) and (GGGGS) $)_{3}$ (Chen et al. 2013)(Fig. 7). The predicted antigenicity of the final construct (194 aa) was 0.5690 (Table 6). A protein BLAST for the final construct was conducted to evaluate the possibility of cross-reactivity. The BLAST result suggested that, except for the SARS-CoV-2 spike protein, no protein would cross-react with the construct (Raw data in the Supplemental Files), which indicated that our fragments possess good specificity.

2

\section{Discussion}

In this study, the immunodominant fragments within the S1 subunit of the SARS-CoV-2 spike protein were explored. The final construct consists of three immunodominant fragments Spike $_{56-94}$, Spike $_{199-264}$, Spike $_{577-612}$, and a PADRE epitope. The recombinant antigen will be used to immunize mice to generate qualified antibody which could be applied for developing an antigen-capture based detection system.

The antibody-based antigen capturing method is user-friendly, time-saving, and economical. Thus, it is an ideal complementary detection strategy especially for early diagnosis and large population screening. The monoclonal antibodies against SARS-CoV have been successfully applied in the immunological antigen-detection of SARS-CoV (Ohnishi 2008). Accordingly, we 
273

274 275

explored the immunodominant fragments on the spike protein of SARS-CoV-2, which would provide aid in developing an accurate and fast antigen-capture based early detection system for SARS-CoV-2.

We selected the S1 subunit for immunodominant fragments screening after divergence analysis. It had been reported that an S1 antigen-based assay of SARS-CoV could capture the virus as soon as the infection occurs (Sunwoo et al. 2013). Jong-Hwan Lee et al. designed a method that could seize and detect spike protein S1 subunit of SARS-CoV-2 using ACE2 receptor and S1-mAb(Lee et al. 2021). This finding suggests that it is appropriate to use the S1 subunit for specific and early diagnosis of SARS-CoV-2. Three immunodominant fragments (Spike $_{56-94}$, Spike $_{199-264}$, and Spike ${ }_{577-612}$ ) were identified in the present study. These sequences will be joined to construct recombinant peptides in the next step. Instead of using inactivated full-length spike protein, we designed a novel recombinant protein construct that increased sequence specificity as well as circumvented mutation sites and glycosylation sites. As the antigen design is based on bioinformatics study, the exact ability of the selected fragments to produce qualified antibodies for virus detection has yet to be determined by experiments. Noticeably, the spike protein of SARS-CoV-2 is heavily glycosylated. Glycans could shield epitopes during antibody recognition, which may interfere with the detection of viral proteins (Shajahan et al. 2020). About $17 \mathrm{~N}$-glycosylation sites along with two O-glycosylation sites were found occupied in the spike protein of SARS-CoV-2(Shajahan et al. 2020). We circumnavigated most glycosylation sites when selecting immunodominant fragments. The three selected fragments in this study only contain 3 glycosylation sites. In case these glycosylation sites 
294 295 296

297 298 300 301 302 303 304 305 306 307 308 309

impede the diagnostic performance, an additional deglycosylation step with N-glycanase should be applied for the test specimens (Dermani et al. 2019), which is a simple and efficient method for deglycosylation (Hirani et al. 1987; Huang et al. 2015; Lattová et al. 2016; Zheng et al. 2011). Alternatively, an eukaryotic expressing system could be employed to mimic the antigen presented in human cells.

Though coronaviruses can find and repair errors during the replication process (Wang et al. 2020b), the SARS-CoV-2 genome still presents a large number of mutations. Mutations could not only help virus slip past our immune defense, but also spoil the efficiency of diagnostic tests (Chen et al. 2020b). In this study, we circumvented high-frequency mutation sites when selecting antigen fragments. In addition, our fragments also avoided RBD regions which are prone to mutation (Chen et al. 2020b). The construct finally built contained no high-frequency mutation. To date, several studies using predictive algorithms to analyze SARS-CoV-2 have been reported(Alam et al. 2020; Behmard et al. 2020; Can et al. 2020; Chen et al. 2020a; Dong et al. 2020; Poran et al. 2020; Saha et al. 2021; Sohail et al. 2021). However, most of these bioinformatics analyses against SARS-CoV-2 intended to develop effective vaccines to prevent infection and the identified sequences possess high homology with other viruses, especially SARS-CoV (Bhattacharya et al. 2020; Chen et al. 2020a; Robson 2020). On the contrary, the fragments suitable for diagnosis should be unique when compared with other species to ensure the specificity of detection. Therefore, the results obtained from vaccine studies are not ideal for virus detection. In this study, attention was paid to the sequences with high variability, hence the immunodominant fragments identified are more specific. Distinct from vaccine studies, murine 
315 MHC alleles were selected in epitopes prediction in this study, so that the designed antigen could

316 trigger a strong humoral immune response in mice. Furthermore, glycosylated sites and recently

317 identified high-frequency mutation sites were deliberately avoided during the screening process

318 to eliminate their potential adverse impact.

319 In silico analysis has been widely used to mine and identify various pathogens as well as epitopes prediction (Kiyotani et al. 2020; Liò \& Goldman 2004; Qin et al. 2003; Robson 2020;

Shen et al. 2003). In this study, identified fragments were further scanned in the IEDB database, and found four peptides contained in the sequences were experimentally validated epitopes

323 (Table S5), which reinforced the conclusion of the present study. In the following studies, we will immunize Balb/c mice with the designed antigen to generate mAbs which could be utilized for SARS-CoV-2 diagnosis after evaluating their sensitivity, specificity, and other related properties.

\section{Conclusion}

Through bioinformatics analysis, three immunodominant fragments were identified in the

present study. After connected by flexible linkers, we acquired a final recombinant peptide with

194 residues. It was predicted to possess high antigenicity and specificity for SARS-CoV-2. Our

next move is to express and purify the recombinant protein in a suitable expression system,

followed by immunizing the mice with purified immunogen to obtain specific antibodies. The 
336

337

338

339

340

341

342

343

344

345

346

347

348

349

350

351

352

353

354

355

356

357

358

359

360

361

362

363

364

365

366

367

368

369

370

371

372

373

374

375

\section{Reference}

Alam A, Khan A, Imam N, Siddiqui M, Waseem M, Malik M, and Ishrat R. 2020. Design of an epitope-based peptide vaccine against the SARS-CoV-2: a vaccine-informatics approach. Briefings in bioinformatics. 10.1093/bib/bbaa340

Alexander J, del Guercio MF, Maewal A, Qiao L, Fikes J, Chesnut RW, Paulson J, Bundle DR, DeFrees S, and Sette A. 2000. Linear PADRE T helper epitope and carbohydrate $B$ cell epitope conjugates induce specific high titer IgG antibody responses. J Immunol 164:1625-1633. 10.4049/jimmunol.164.3.1625

Altschul SF, Madden TL, Schäffer AA, Zhang J, Zhang Z, Miller W, and Lipman DJ. 1997. Gapped BLAST and PSIBLAST: a new generation of protein database search programs. Nucleic Acids Res 25:3389-3402. 10.1093/nar/25.17.3389

Behmard E, Soleymani B, Najafi A, and Barzegari E. 2020. Immunoinformatic design of a COVID-19 subunit vaccine using entire structural immunogenic epitopes of SARS-CoV-2. Scientific reports 10:20864. 10.1038/s41598-020-77547-4

Bhattacharya M, Sharma AR, Patra P, Ghosh P, Sharma G, Patra BC, Lee SS, and Chakraborty C. 2020. Development of epitope-based peptide vaccine against novel coronavirus 2019 (SARS-COV-2): Immunoinformatics approach. J Med Virol 92:618-631. 10.1002/jmv.25736

Bustin SA, and Nolan T. 2020. RT-qPCR Testing of SARS-CoV-2: A Primer. Int J Mol Sci 21. 10.3390/ijms21083004

Callebaut P, Enjuanes L, and Pensaert M. 1996. An adenovirus recombinant expressing the spike glycoprotein of porcine respiratory coronavirus is immunogenic in swine. J Gen Virol 77 ( Pt 2 ):309-313. 10.1099/00221317-77-2-309

Can H, Köseoğlu AE, Erkunt Alak S, Güvendi M, Döşkaya M, Karakavuk M, Gürüz AY, and Ün C. 2020. In silico discovery of antigenic proteins and epitopes of SARS-CoV-2 for the development of a vaccine or a diagnostic approach for COVID-19. Sci Rep 10:22387. 10.1038/s41598-020-79645-9

Cazares LH, Chaerkady R, Samuel Weng SH, Boo CC, Cimbro R, Hsu HE, Rajan S, Dall'Acqua W, Clarke L, Ren K, McTamney P, Kallewaard-LeLay N, Ghaedi M, Ikeda Y, and Hess S. 2020. Development of a Parallel Reaction Monitoring Mass Spectrometry Assay for the Detection of SARS-CoV-2 Spike Glycoprotein and Nucleoprotein. Anal Chem 92:13813-13821. 10.1021/acs.analchem.0c02288

Chen HZ, Tang LL, Yu XL, Zhou J, Chang YF, and Wu X. 2020a. Bioinformatics analysis of epitope-based vaccine design against the novel SARS-CoV-2. Infect Dis Poverty 9:88. 10.1186/s40249-020-00713-3

Chen J, Wang R, Wang M, and Wei GW. 2020b. Mutations Strengthened SARS-CoV-2 Infectivity. J Mol Biol 432:5212-5226. 10.1016/j.jmb.2020.07.009

Chen J, Zhu H, Horby PW, Wang Q, Zhou J, Jiang H, Liu L, Zhang T, Zhang Y, Chen X, Deng X, Nikolay B, Wang W, Cauchemez S, Guan Y, Uyeki TM, and Yu H. 2020c. Specificity, kinetics and longevity of antibody responses to avian influenza A(H7N9) virus infection in humans. J Infect 80:310-319. 10.1016/j.jinf.2019.11.024

Chen X, Zaro JL, and Shen WC. 2013. Fusion protein linkers: property, design and functionality. Adv Drug Deliv Rev 65:1357-1369. 10.1016/j.addr.2012.09.039

Cho S, Raybuck A, Blagih J, Kemboi E, Haase V, Jones R, and Boothby M. 2019a. Hypoxia-inducible factors in CD4 T cells promote metabolism, switch cytokine secretion, and T cell help in humoral immunity. Proceedings of the National Academy of Sciences of the United States of America 116:8975-8984. 10.1073/pnas.1811702116

Peer] reviewing PDF | (2020:12:56038:1:2:NEW 1 Mar 2021) 
Cho SH, Raybuck AL, Blagih J, Kemboi E, Haase VH, Jones RG, and Boothby MR. 2019b. Hypoxia-inducible factors in CD4(+) T cells promote metabolism, switch cytokine secretion, and T cell help in humoral immunity. Proc Natl Acad Sci U S A 116:8975-8984. 10.1073/pnas.1811702116

Dermani FK, Samadi P, Rahmani G, Kohlan AK, and Najafi R. 2019. PD-1/PD-L1 immune checkpoint: Potential target for cancer therapy. J Cell Physiol 234:1313-1325. 10.1002/jcp.27172

Dimitrov I, Bangov I, Flower DR, and Doytchinova I. 2014. AllerTOP v.2--a server for in silico prediction of allergens. J Mol Model 20:2278. 10.1007/s00894-014-2278-5

Dong R, Chu Z, Yu F, and Zha Y. 2020. Contriving Multi-Epitope Subunit of Vaccine for COVID-19: Immunoinformatics Approaches. Frontiers in immunology 11:1784. 10.3389/fimmu.2020.01784

Doytchinova IA, and Flower DR. 2007. VaxiJen: a server for prediction of protective antigens, tumour antigens and subunit vaccines. BMC Bioinformatics 8:4. 10.1186/1471-2105-8-4

Fehr AR, and Perlman S. 2015. Coronaviruses: an overview of their replication and pathogenesis. Methods Mol Biol 1282:1-23. 10.1007/978-1-4939-2438-7_1

Getzoff ED, Tainer JA, Lerner RA, and Geysen HM. 1988. The chemistry and mechanism of antibody binding to protein antigens. Adv Immunol 43:1-98. 10.1016/s0065-2776(08)60363-6

Ghaffari-Nazari H, Tavakkol-Afshari J, Jaafari MR, Tahaghoghi-Hajghorbani S, Masoumi E, and Jalali SA. 2015. Improving Multi-Epitope Long Peptide Vaccine Potency by Using a Strategy that Enhances CD4+ T Help in BALB/c Mice. PLoS One 10:e0142563. 10.1371/journal.pone.0142563

Gomez N, Carrillo C, Salinas J, Parra F, Borca MV, and Escribano JM. 1998. Expression of immunogenic glycoprotein $S$ polypeptides from transmissible gastroenteritis coronavirus in transgenic plants. Virology 249:352-358. 10.1006/viro.1998.9315

Gupta S, Kapoor P, Chaudhary K, Gautam A, Kumar R, Open Source Drug Discovery C, and Raghava GP. 2013. In silico approach for predicting toxicity of peptides and proteins. PLoS One 8:e73957. 10.1371/journal.pone.0073957

Hachim A, Kavian N, Cohen CA, Chin AWH, Chu DKW, Mok CKP, Tsang OTY, Yeung YC, Perera R, Poon LLM, Peiris JSM, and Valkenburg SA. 2020. ORF8 and ORF3b antibodies are accurate serological markers of early and late SARS-CoV-2 infection. Nat Immunol 21:1293-1301. 10.1038/s41590-020-0773-7

Hirani S, Bernasconi RJ, and Rasmussen JR. 1987. Use of N-glycanase to release asparagine-linked oligosaccharides for structural analysis. Anal Biochem 162:485-492. 10.1016/0003-2697(87)90424-6

Huang J, Wan H, Yao Y, Li J, Cheng K, Mao J, Chen J, Wang Y, Qin H, Zhang W, Ye M, and Zou H. 2015. Highly Efficient Release of Glycopeptides from Hydrazide Beads by Hydroxylamine Assisted PNGase $\mathrm{F}$ Deglycosylation for N-Glycoproteome Analysis. Anal Chem 87:10199-10204. 10.1021/acs.analchem.5b02669

Ishige T, Murata S, Taniguchi T, Miyabe A, Kitamura K, Kawasaki K, Nishimura M, Igari H, and Matsushita K. 2020. Highly sensitive detection of SARS-CoV-2 RNA by multiplex rRT-PCR for molecular diagnosis of COVID-19 by clinical laboratories. Clin Chim Acta 507:139-142. 10.1016/j.cca.2020.04.023

Jespersen MC, Peters B, Nielsen M, and Marcatili P. 2017. BepiPred-2.0: improving sequence-based B-cell epitope prediction using conformational epitopes. Nucleic Acids Res 45:W24-W29. 10.1093/nar/gkx346

Ji Y, Guo W, Zhao L, Li H, Lu G, Wang Z, Wang G, Liu C, and Xiang W. 2011. Development of an antigen-capture ELISA for the detection of equine influenza virus nucleoprotein. J Virol Methods 175:120-124. 10.1016/j.jviromet.2011.04.016

Peer) reviewing PDF | (2020:12:56038:1:2:NEW 1 Mar 2021) 
417

418

419

420

421

422

423

424

425

426

427

428

429

430

431

432

433

434

435

436

437

438

439

440

441

442

443

444

445

446

447

448

449

450

451

452

453

454

455

456

457

Kin N, Miszczak F, Lin W, Gouilh MA, Vabret A, and Consortium E. 2015. Genomic Analysis of 15 Human Coronaviruses OC43 (HCoV-OC43s) Circulating in France from 2001 to 2013 Reveals a High Intra-Specific Diversity with New Recombinant Genotypes. Viruses 7:2358-2377. 10.3390/v7052358

Kiyotani K, Toyoshima Y, Nemoto K, and Nakamura Y. 2020. Bioinformatic prediction of potential T cell epitopes for SARS-Cov-2. J Hum Genet 65:569-575. 10.1038/s10038-020-0771-5

Kumar S, Maurya VK, Prasad AK, Bhatt MLB, and Saxena SK. 2020. Structural, glycosylation and antigenic variation between 2019 novel coronavirus (2019-nCoV) and SARS coronavirus (SARS-CoV). Virusdisease 31:13-21. 10.1007/s13337-020-00571-5

Lan J, Ge J, Yu J, Shan S, Zhou H, Fan S, Zhang Q, Shi X, Wang Q, Zhang L, and Wang X. 2020. Structure of the SARSCoV-2 spike receptor-binding domain bound to the ACE2 receptor. Nature. 10.1038/s41586-020-2180-5

Lattová E, Bryant J, Skřičková J, Zdráhal Z, and Popovič M. 2016. Efficient Procedure for N-Glycan Analyses and Detection of Endo H-Like Activity in Human Tumor Specimens. J Proteome Res 15:2777-2786. 10.1021/acs.jproteome.6b00346

Lee JH, Choi M, Jung Y, Lee SK, Lee CS, Kim J, Kim J, Kim NH, Kim BT, and Kim HG. 2021. A novel rapid detection for SARS-CoV-2 spike 1 antigens using human angiotensin converting enzyme 2 (ACE2). Biosens Bioelectron 171:112715. 10.1016/j.bios.2020.112715

Li Q, Wu J, Nie J, Zhang L, Hao H, Liu S, Zhao C, Zhang Q, Liu H, Nie L, Qin H, Wang M, Lu Q, Li X, Sun Q, Liu J, Zhang L, Li X, Huang W, and Wang Y. 2020. The Impact of Mutations in SARS-CoV-2 Spike on Viral Infectivity and Antigenicity. Cell 182:1284-1294.e1289. 10.1016/j.cell.2020.07.012

Liò P, and Goldman N. 2004. Phylogenomics and bioinformatics of SARS-CoV. Trends Microbiol 12:106-111. 10.1016/j.tim.2004.01.005

Liu W, Liu L, Kou G, Zheng Y, Ding Y, Ni W, Wang Q, Tan L, Wu W, Tang S, Xiong Z, and Zheng S. 2020. Evaluation of Nucleocapsid and Spike Protein-based ELISAs for detecting antibodies against SARS-CoV-2. J Clin Microbiol. 10.1128/JCM.00461-20

Lu L, Manopo I, Leung BP, Chng HH, Ling AE, Chee LL, Ooi EE, Chan SW, and Kwang J. 2004. Immunological characterization of the spike protein of the severe acute respiratory syndrome coronavirus. J Clin Microbiol 42:1570-1576. 10.1128/jcm.42.4.1570-1576.2004

Mahon BP, Katrak K, Nomoto A, Macadam AJ, Minor PD, and Mills KH. 1995. Poliovirus-specific CD4+ Th1 clones with both cytotoxic and helper activity mediate protective humoral immunity against a lethal poliovirus infection in transgenic mice expressing the human poliovirus receptor. J Exp Med 181:1285-1292. 10.1084/jem.181.4.1285

Meyer B, Drosten C, and Muller MA. 2014. Serological assays for emerging coronaviruses: challenges and pitfalls. Virus Res 194:175-183. 10.1016/j.virusres.2014.03.018

Mu F, Niu D, Mu J, He B, Han W, Fan B, Huang S, Qiu Y, You B, and Chen W. 2008. The expression and antigenicity of a truncated spike-nucleocapsid fusion protein of severe acute respiratory syndrome-associated coronavirus. BMC Microbiol 8:207. 10.1186/1471-2180-8-207

Needleman SB, and Wunsch CD. 1970. A general method applicable to the search for similarities in the amino acid sequence of two proteins. J Mol Biol 48:443-453. 10.1016/0022-2836(70)90057-4

Ohnishi K. 2008. Establishment and characterization of monoclonal antibodies against SARS coronavirus. Methods Mol Biol 454:191-203. 10.1007/978-1-59745-181-9_15

Ohnishi K, Sakaguchi M, Kaji T, Akagawa K, Taniyama T, Kasai M, Tsunetsugu-Yokota Y, Oshima M, Yamamoto K, 
458

459

460

461

462

463

464

465

466

467

468

469

470

471

472

473

474

475

476

477

478

479

480

481

482

483

484

485

486

487

488

489

490

491

492

493

494

495

496

497

498

Takasuka N, Hashimoto S, Ato M, Fujii H, Takahashi Y, Morikawa S, Ishii K, Sata T, Takagi H, Itamura S, Odagiri T, Miyamura T, Kurane I, Tashiro M, Kurata T, Yoshikura H, and Takemori T. 2005. Immunological detection of severe acute respiratory syndrome coronavirus by monoclonal antibodies. Jpn J Infect Dis 58:88-94.

Ohnishi K, Takahashi Y, Kono N, Nakajima N, Mizukoshi F, Misawa S, Yamamoto T, Mitsuki YY, Fu S, Hirayama N, Ohshima M, Ato M, Kageyama T, Odagiri T, Tashiro M, Kobayashi K, Itamura S, and Tsunetsugu-Yokota Y. 2012. Newly established monoclonal antibodies for immunological detection of H5N1 influenza virus. Jpn $\mathrm{J}$ Infect Dis 65:19-27.

Padoan A, Cosma C, Sciacovelli L, Faggian D, and Plebani M. 2020. Analytical performances of a chemiluminescence immunoassay for SARS-CoV-2 IgM/IgG and antibody kinetics. Clin Chem Lab Med. 10.1515/cclm-20200443

Paul S, Sidney J, Sette A, and Peters B. 2016. TepiTool: A Pipeline for Computational Prediction of T Cell Epitope Candidates. Curr Protoc Immunol 114:18 19 11-18 19 24. 10.1002/cpim.12

Paus D, Phan T, Chan T, Gardam S, Basten A, and Brink R. 2006. Antigen recognition strength regulates the choice between extrafollicular plasma cell and germinal center B cell differentiation. The Journal of experimental medicine 203:1081-1091. 10.1084/jem.20060087

Petersen B, Petersen TN, Andersen P, Nielsen M, and Lundegaard C. 2009. A generic method for assignment of reliability scores applied to solvent accessibility predictions. BMC Struct Biol 9:51. 10.1186/1472-6807-951

Poran A, Harjanto D, Malloy M, Arieta C, Rothenberg D, Lenkala D, van Buuren M, Addona T, Rooney M, Srinivasan L, and Gaynor R. 2020. Sequence-based prediction of SARS-CoV-2 vaccine targets using a mass spectrometry-based bioinformatics predictor identifies immunogenic T cell epitopes. Genome medicine 12:70. 10.1186/s13073-020-00767-w

Qin L, Xiong B, Luo C, Guo ZM, Hao P, Su J, Nan P, Feng Y, Shi YX, Yu XJ, Luo XM, Chen KX, Shen X, Shen JH, Zou JP, Zhao GP, Shi TL, He WZ, Zhong Y, Jiang HL, and Li YX. 2003. Identification of probable genomic packaging signal sequence from SARS-CoV genome by bioinformatics analysis. Acta Pharmacol Sin 24:489-496.

Qiu LW, Tang HW, Wang YD, Liao JE, Hao W, Wen K, He XM, and Che XY. 2005. [Development and application of triple antibodies-based sandwich ELISA for detecting nucleocapsid protein of SARS-associated coronavirus]. Zhonghua Liu Xing Bing Xue Za Zhi 26:277-281.

Robson B. 2020. Computers and viral diseases. Preliminary bioinformatics studies on the design of a synthetic vaccine and a preventative peptidomimetic antagonist against the SARS-CoV-2 (2019-nCoV, COVID-19) coronavirus. Comput Biol Med 119:103670. 10.1016/j.compbiomed.2020.103670

Rothe C, Schunk M, Sothmann P, Bretzel G, Froeschl G, Wallrauch C, Zimmer T, Thiel V, Janke C, Guggemos W, Seilmaier M, Drosten C, Vollmar P, Zwirglmaier K, Zange S, Wolfel R, and Hoelscher M. 2020. Transmission of 2019-nCoV Infection from an Asymptomatic Contact in Germany. N Engl J Med 382:970-971. 10.1056/NEJMc2001468

Saha R, Ghosh P, and Burra V. 2021. Designing a next generation multi-epitope based peptide vaccine candidate against SARS-CoV-2 using computational approaches. 3 Biotech 11:47. 10.1007/s13205-020-02574-x

Saha S, and Raghava GP. 2006. Prediction of continuous B-cell epitopes in an antigen using recurrent neural network. Proteins 65:40-48. 10.1002/prot.21078

Sanchez CM, Izeta A, Sanchez-Morgado JM, Alonso S, Sola I, Balasch M, Plana-Duran J, and Enjuanes L. 1999.

Peer] reviewing PDF | (2020:12:56038:1:2:NEW 1 Mar 2021) 
499

500

501

502

503

504

505

506

507

508

509

510

511

512

513

514

515

516

517

518

519

520

521

522

523

524

525

526

527

528

529

530

531

532

533

534

535

536

537

538

539

Targeted recombination demonstrates that the spike gene of transmissible gastroenteritis coronavirus is a determinant of its enteric tropism and virulence. J Virol 73:7607-7618.

Shajahan A, Supekar NT, Gleinich AS, and Azadi P. 2020. Deducing the N- and O- glycosylation profile of the spike protein of novel coronavirus SARS-CoV-2. Glycobiology. 10.1093/glycob/cwaa042

Shaman J, and Galanti M. 2020. Will SARS-CoV-2 become endemic? Science 370:527-529. 10.1126/science.abe5960

Shang J, Ye G, Shi K, Wan Y, Luo C, Aihara H, Geng Q, Auerbach A, and Li F. 2020. Structural basis of receptor recognition by SARS-CoV-2. Nature. 10.1038/s41586-020-2179-y

Shen X, Xue JH, Yu CY, Luo HB, Qin L, Yu XJ, Chen J, Chen LL, Xiong B, Yue LD, Cai JH, Shen JH, Luo XM, Chen KX, Shi TL, Li YX, Hu GX, and Jiang HL. 2003. Small envelope protein E of SARS: cloning, expression, purification, CD determination, and bioinformatics analysis. Acta Pharmacol Sin 24:505-511.

Shulman Z, Gitlin A, Weinstein J, Lainez B, Esplugues E, Flavell R, Craft J, and Nussenzweig M. 2014. Dynamic signaling by $T$ follicular helper cells during germinal center B cell selection. Science (New York, NY) 345:1058-1062. 10.1126/science.1257861

Sievers F, Wilm A, Dineen D, Gibson TJ, Karplus K, Li W, Lopez R, McWilliam H, Remmert M, Soding J, Thompson JD, and Higgins DG. 2011. Fast, scalable generation of high-quality protein multiple sequence alignments using Clustal Omega. Mol Syst Biol 7:539. 10.1038/msb.2011.75

Sohail M, Ahmed S, Quadeer A, and McKay M. 2021. In silico T cell epitope identification for SARS-CoV-2: Progress and perspectives. Advanced drug delivery reviews. 10.1016/j.addr.2021.01.007

Su S, Wong G, Shi W, Liu J, Lai ACK, Zhou J, Liu W, Bi Y, and Gao GF. 2016. Epidemiology, Genetic Recombination, and Pathogenesis of Coronaviruses. Trends Microbiol 24:490-502. 10.1016/j.tim.2016.03.003

Sunwoo HH, Palaniyappan A, Ganguly A, Bhatnagar PK, Das D, El-Kadi AO, and Suresh MR. 2013. Quantitative and sensitive detection of the SARS-CoV spike protein using bispecific monoclonal antibody-based enzymelinked immunoassay. J Virol Methods 187:72-78. 10.1016/j.jviromet.2012.09.006

Tan YJ, Goh PY, Fielding BC, Shen S, Chou CF, Fu JL, Leong HN, Leo YS, Ooi EE, Ling AE, Lim SG, and Hong W. 2004. Profiles of antibody responses against severe acute respiratory syndrome coronavirus recombinant proteins and their potential use as diagnostic markers. Clin Diagn Lab Immunol 11:362-371. 10.1128/cdli.11.2.362-371.2004

Tang MS, Hock KG, Logsdon NM, Hayes JE, Gronowski AM, Anderson NW, and Farnsworth CW. 2020. Clinical Performance of Two SARS-CoV-2 Serologic Assays. Clin Chem. 10.1093/clinchem/hvaa120

Tegally H, Wilkinson E, Giovanetti M, Iranzadeh A, Fonseca V, Giandhari J, Doolabh D, Pillay S, San EJ, Msomi N, Mlisana K, von Gottberg A, Walaza S, Allam M, Ismail A, Mohale T, Glass AJ, Engelbrecht S, Van Zyl G, Preiser W, Petruccione F, Sigal A, Hardie D, Marais G, Hsiao M, Korsman S, Davies M-A, Tyers L, Mudau I, York D, Maslo C, Goedhals D, Abrahams S, Laguda-Akingba O, Alisoltani-Dehkordi A, Godzik A, Wibmer CK, Sewell BT, Lourenço J, Alcantara LCJ, Pond SLK, Weaver S, Martin D, Lessells RJ, Bhiman JN, Williamson C, and de Oliveira T. 2020. Emergence and rapid spread of a new severe acute respiratory syndrome-related coronavirus 2 (SARS-CoV-2) lineage with multiple spike mutations in South Africa. medRxiv 10.1101/2020.12.21.20248640

Thabet L, Mhalla S, Naija H, Jaoua MA, Hannachi N, Fki-Berrajah L, Toumi A, and Karray-Hakim H. 2020. SARS-CoV-2 infection virological diagnosis. Tunis Med 98:304-308.

Trolle T, Metushi IG, Greenbaum JA, Kim Y, Sidney J, Lund O, Sette A, Peters B, and Nielsen M. 2015. Automated benchmarking of peptide-MHC class I binding predictions. Bioinformatics 31:2174-2181.

Peer] reviewing PDF | (2020:12:56038:1:2:NEW 1 Mar 2021) 
10.1093/bioinformatics/btv123

Vita R, Mahajan S, Overton JA, Dhanda SK, Martini S, Cantrell JR, Wheeler DK, Sette A, and Peters B. 2019. The Immune Epitope Database (IEDB): 2018 update. Nucleic Acids Res 47:D339-d343. 10.1093/nar/gky1006

Walls AC, Xiong X, Park YJ, Tortorici MA, Snijder J, Quispe J, Cameroni E, Gopal R, Dai M, Lanzavecchia A, Zambon M, Rey FA, Corti D, and Veesler D. 2019. Unexpected Receptor Functional Mimicry Elucidates Activation of Coronavirus Fusion. Cell 176:1026-1039.e1015. 10.1016/j.cell.2018.12.028

Wang P, Sidney J, Kim Y, Sette A, Lund O, Nielsen M, and Peters B. 2010. Peptide binding predictions for HLA DR, DP and DQ molecules. BMC Bioinformatics 11:568. 10.1186/1471-2105-11-568

Wang R, Hozumi Y, Yin C, and Wei G-W. 2020a. Mutations on COVID-19 diagnostic targets. Genomics 112:52045213. 10.1016/j.ygeno.2020.09.028

Wang R, Hozumi Y, Yin C, and Wei GW. 2020b. Decoding SARS-CoV-2 Transmission and Evolution and Ramifications for COVID-19 Diagnosis, Vaccine, and Medicine. J Chem Inf Model. 10.1021/acs.jcim.0c00501

Wilkins MR, Gasteiger E, Bairoch A, Sanchez JC, Williams KL, Appel RD, and Hochstrasser DF. 1999. Protein identification and analysis tools in the ExPASy server. Methods Mol Biol 112:531-552. 10.1385/1-59259584-7:531

Woo PC, Lau SK, Wong BH, Tsoi HW, Fung AM, Kao RY, Chan KH, Peiris JS, and Yuen KY. 2005. Differential sensitivities of severe acute respiratory syndrome (SARS) coronavirus spike polypeptide enzyme-linked immunosorbent assay (ELISA) and SARS coronavirus nucleocapsid protein ELISA for serodiagnosis of SARS coronavirus pneumonia. J Clin Microbiol 43:3054-3058. 10.1128/JCM.43.7.3054-3058.2005

Yan Y, Chang L, and Wang L. 2020. Laboratory testing of SARS-CoV, MERS-CoV, and SARS-CoV-2 (2019-nCoV): Current status, challenges, and countermeasures. Rev Med Virol 30:e2106. 10.1002/rmv.2106

Yuan S, Chan HCS, Filipek S, and Vogel H. 2016. PyMOL and Inkscape Bridge the Data and the Data Visualization. Structure 24:2041-2042. 10.1016/j.str.2016.11.012

Zhan SH, Deverman BE, and Chan YA. 2020. 10.1101/2020.05.01.073262

Zhang L, Udaka K, Mamitsuka H, and Zhu S. 2012. Toward more accurate pan-specific MHC-peptide binding prediction: a review of current methods and tools. Brief Bioinform 13:350-364. 10.1093/bib/bbr060

Zheng K, Bantog C, and Bayer R. 2011. The impact of glycosylation on monoclonal antibody conformation and stability. MAbs 3:568-576. 10.4161/mabs.3.6.17922 
Figure 1

Work flow chart

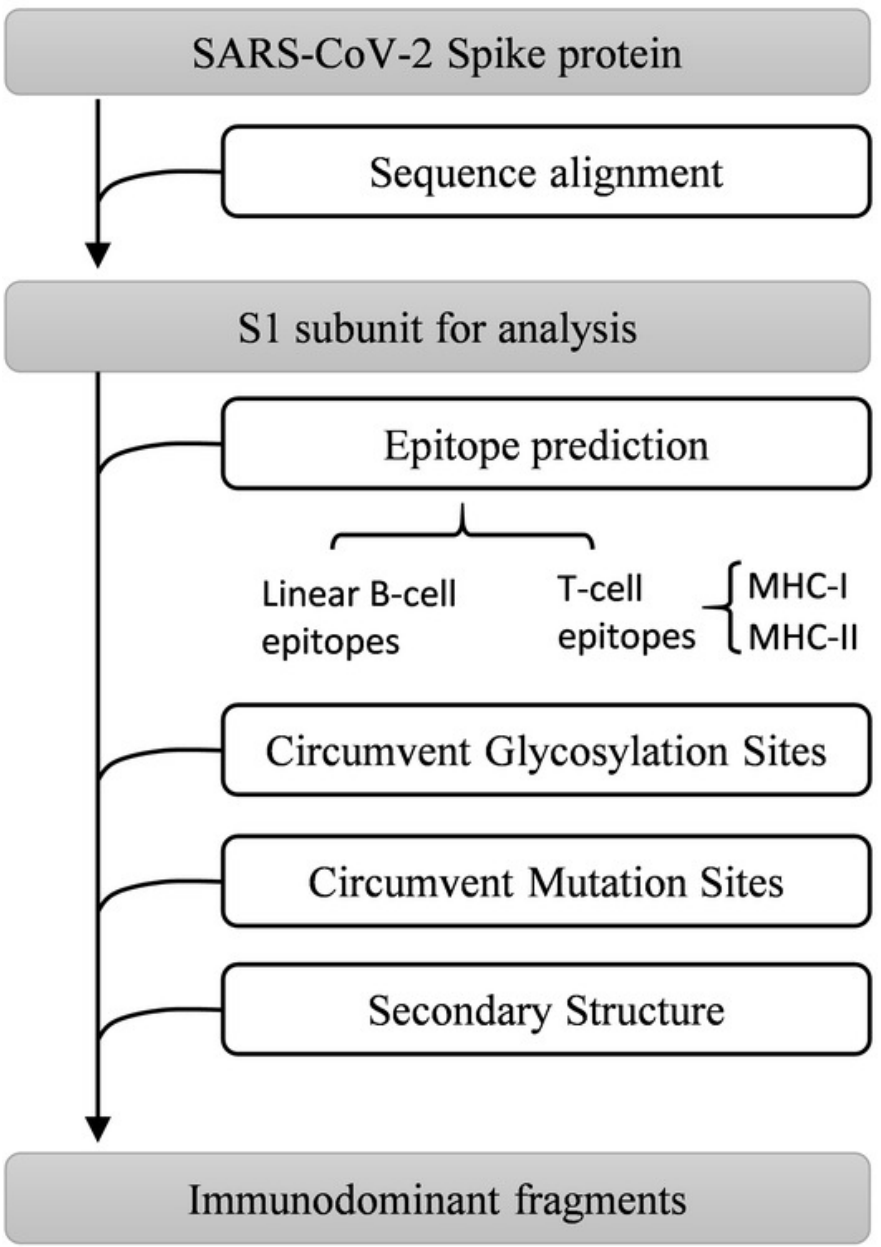

Recombinant antigen

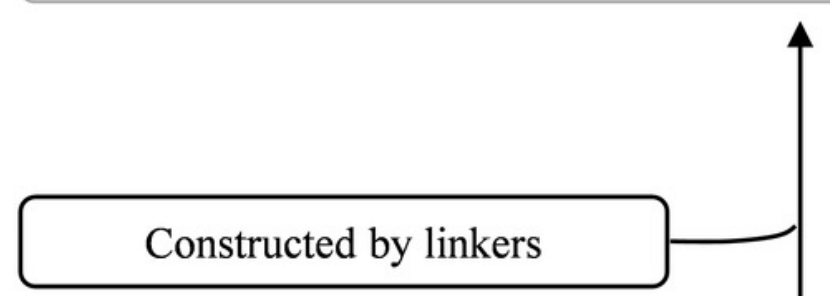

Evaluation of immunodominant fragments
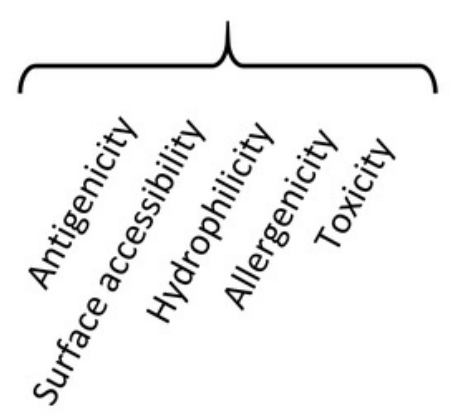

Immunodominant fragments 
Figure 2

Sequence alignment results of spike protein

A. Accession IDs and sequence identities of selected coronavirus spike protein. B.

Phylogenetic tree of spike proteins among selected coronavirus. C. Sequence identity of major domains in spike protein between SARS-CoV-2 and SARS-CoV. D. Sequence identity of domains in SARS-CoV-2 and SARS-CoV reflected by colors. From red to green, the color changing represents the sequence identity from high to low.

A

\begin{tabular}{ccc}
\hline Virus & Accession ID & Identity compared to SARS-CoV-2(\%) \\
\hline SARS-CoV-2 & QIC53213.1 & 100 \\
SARS-COV & ABD72968.1 & 77.46 \\
MERS-COV & QBM11748.1 & 32.04 \\
HCoV-NL63 & YP_003767.1 & 25.57 \\
HCoV-229E & AWH62679.1 & 26.90 \\
HCoV-OC43 & AIX10763.1 & 30.92 \\
HCoV-HKU1 & AMN88694.1 & 29.92 \\
\hline
\end{tabular}

B

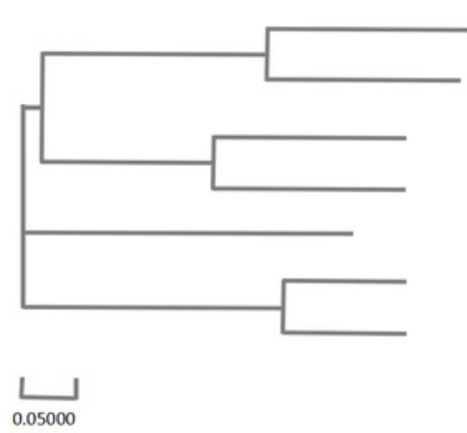

HCOV-NL63 (0.19044)

HCoV-229E (0.17726)

HCoV-OC43 (0.17523)

MERS-COV (0.3304)

SARS-CoV-2 (0.1128)

SARS-COV (0.11262)
HCoV-HKU1 (0.17646)

C

\begin{tabular}{ccc}
\hline Domains & Length & Identity (\%) \\
\hline Spike protein & 1277 & 76.4 \\
S1 subunit & 68.9 & 64.6 \\
NTD & 304 & 50.0 \\
RBM & 71 & 49.3 \\
RBD & 222 & 73.0 \\
S2 subunit & 588 & 90.0 \\
\hline
\end{tabular}

s1 Subunit

S2 Subunit

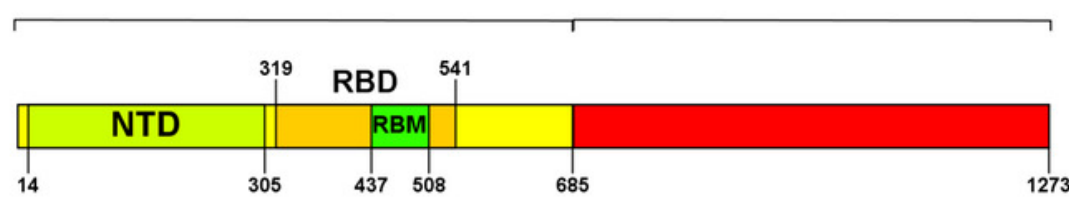

SARS-CoV

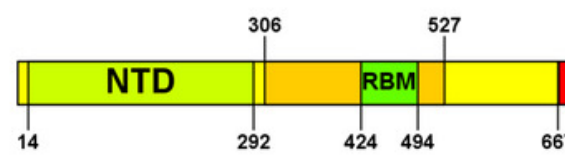

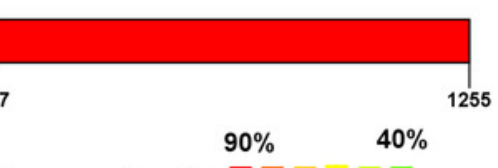

Sequence identity 
Figure 3

Preliminary immunodominant fragments based on B-cell epitope prediction results

The black squares represent epitopes predicted by ABCpred server, the black frames represent epitopes predicted by Bepipred V2.0 server, and the black lines with numbers on both ends represent the preliminary candidate immunodominant fragments.

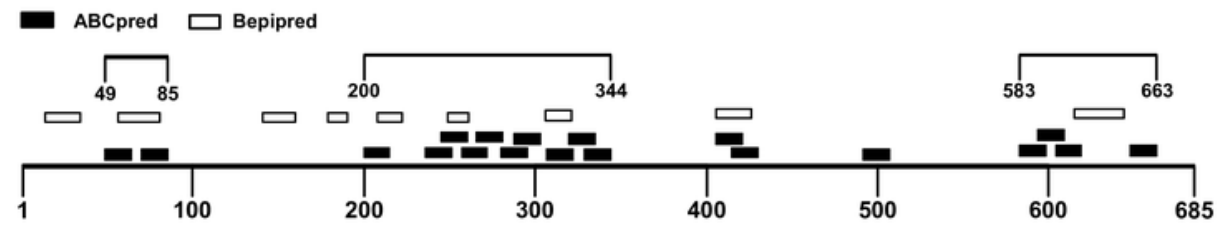


Figure 4

Adjusted candidate immunodominant fragments according to MHC-II T-cell epitope prediction results

The black squares represent epitopes predicted by ABCpred server, and the black frames represent epitopes predicted by Bepipred v2.0 server. The red frames denote MHC-II binding epitopes. The black lines with numbers on both ends represent the adjusted candidate fragments.

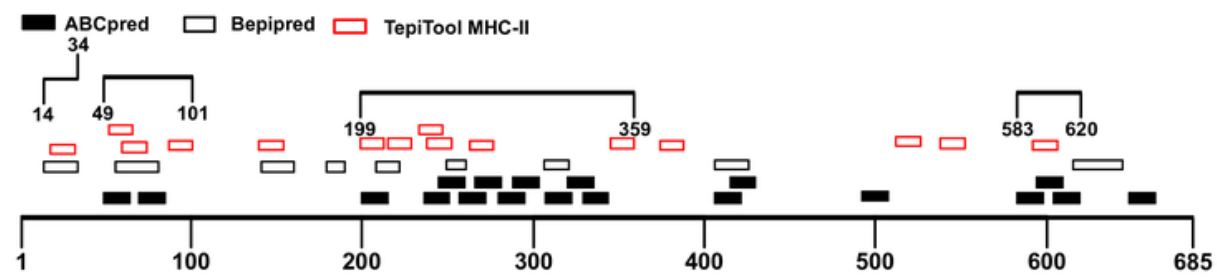




\section{Figure 5}

The epitopes and glycosylation sites on the selected immunodominant fragments

The black squares represent epitopes predicted by $A B C$ pred server, and the black frames represent epitopes predicted by Bepipred v2.0 server. The red squares represent MHC-I binding epitopes, and the red frames represent MHC-II binding epitopes. The grey squares means occupied glycosylation sites contained in the selected fragments. 

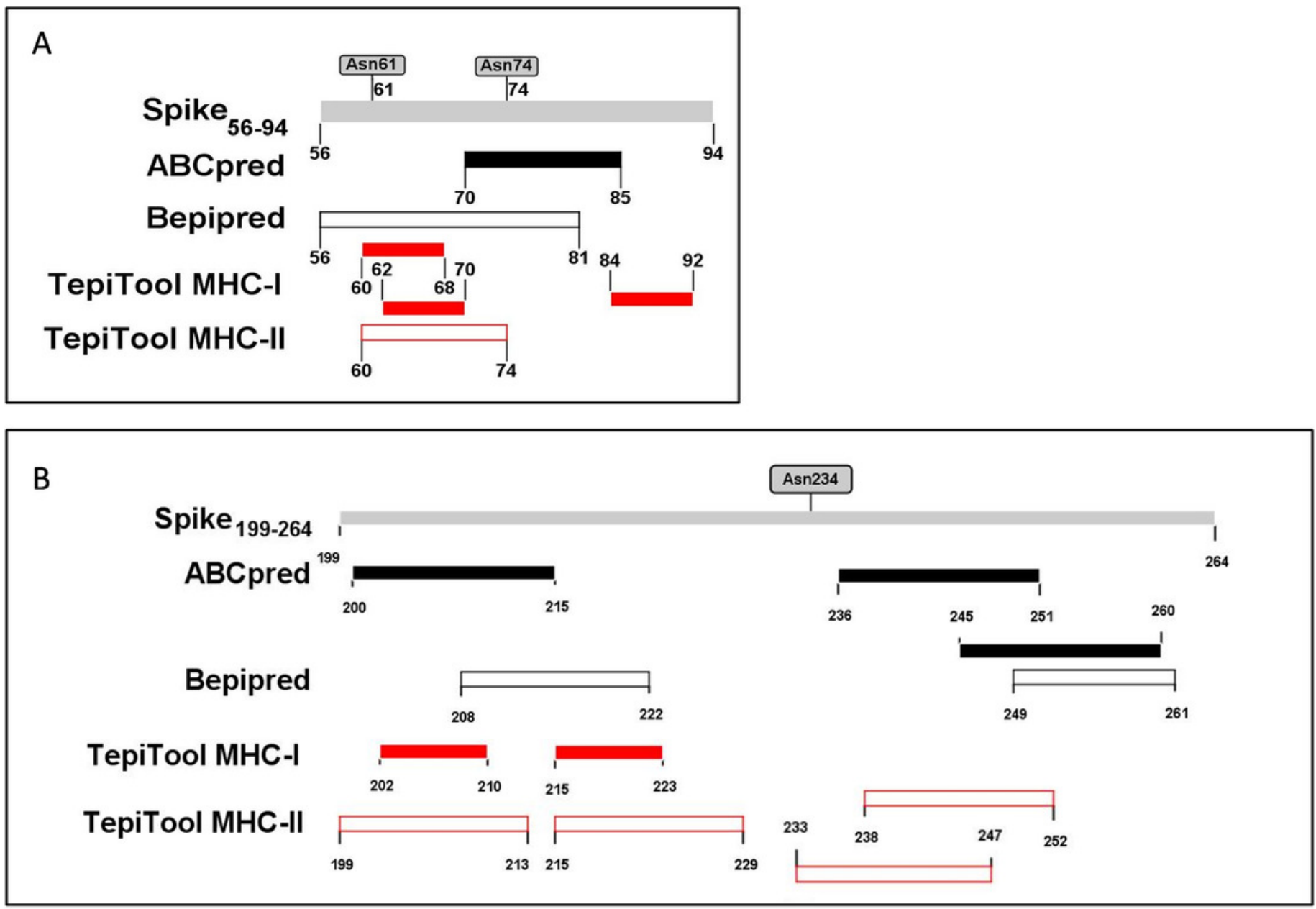

C Spike ${ }_{577-612}$ ABCpred

TepiTool MHC-II

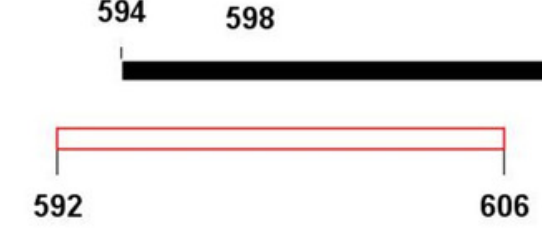


Figure 6

Selected immunodominant fragments presented as spheres in the trimer structure of spike protein viewed by PyMOL

Selected fragments were presented as red spheres, green cartoons denote unselected sections. A, B, and C denote fragments Spike56-94, Spike199-264, and Spike577-612 respectively.
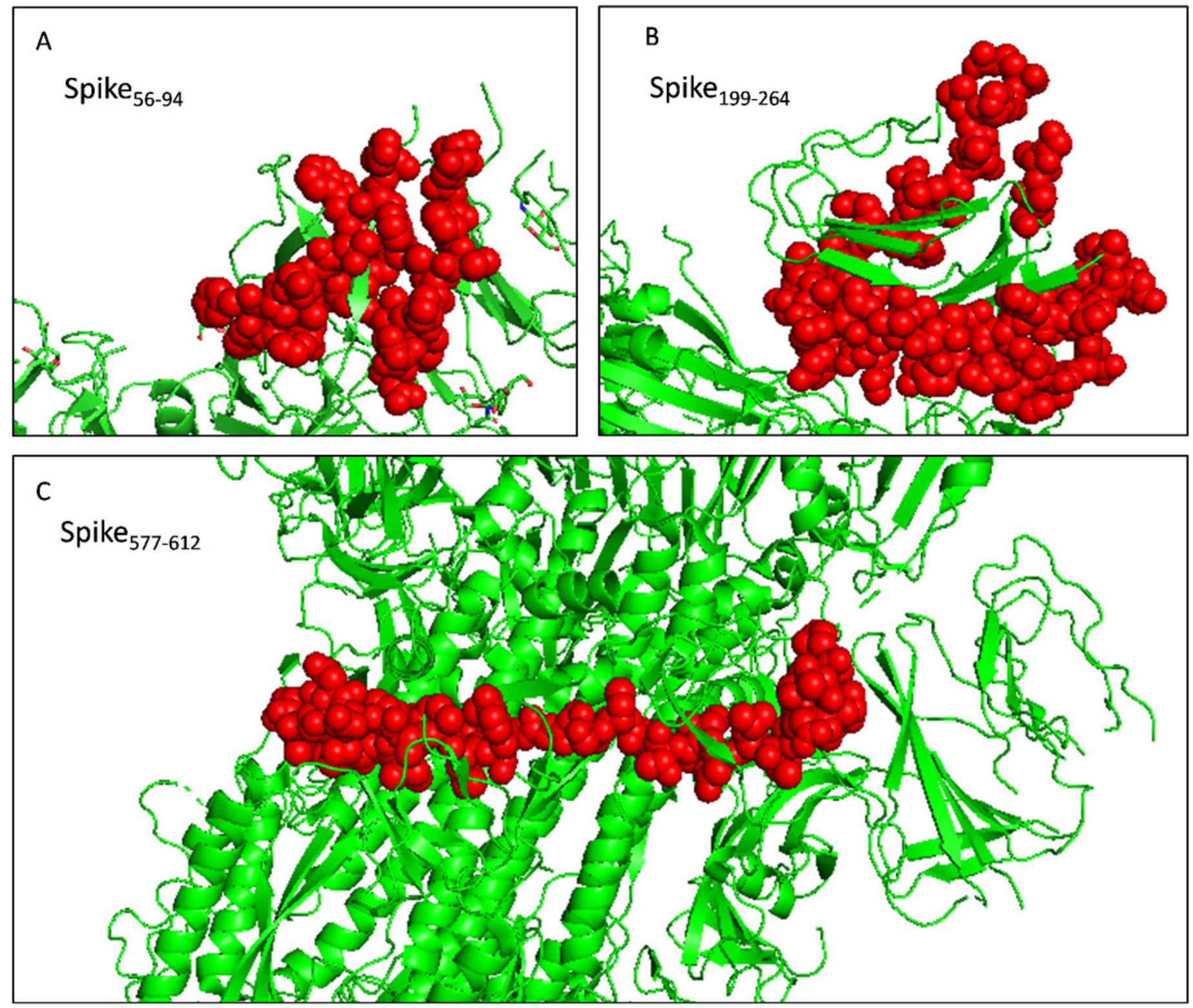
Figure 7

A schematic diagram of recombinant peptide composed of selected fragments and a PADRE epitope.

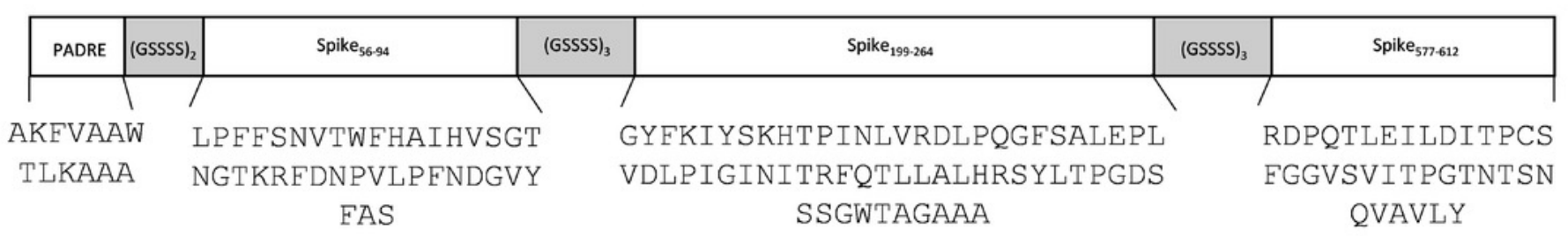




\section{Table $\mathbf{1}$ (on next page)}

Linear B-cell epitopes predicted by ABCpred and BepiPred V2.0 with antigenicity score exceed the threshold value 


\begin{tabular}{|c|c|c|c|c|}
\hline Tools & Position & Sequence & Length & $\begin{array}{l}\text { Antigenicity } \\
\text { (cut off } \geq 0.4 \text { ) }\end{array}$ \\
\hline \multirow{19}{*}{ ABCpred } & $583-598$ & EILDITPCSFGGVSVI & 16 & 1.3971 \\
\hline & $406-421$ & EVRQIAPGQTGKIADY & 16 & 1.3837 \\
\hline & $415-430$ & TGKIADYNYKLPDDFT & 16 & 0.9642 \\
\hline & $648-663$ & GCLIGAEHVNNSYECD & 16 & 0.848 \\
\hline & $288-303$ & AVDCALDPLSETKCTL & 16 & 0.7905 \\
\hline & $604-619$ & TSNQVAVLYQDVNCTE & 16 & 0.7593 \\
\hline & $307-322$ & TVEKGIYQTSNFRVQP & 16 & 0.6733 \\
\hline & $200-215$ & YFKIYSKHTPINLVRD & 16 & 0.657 \\
\hline & $257-272$ & GWTAGAAAYYVGYLQP & 16 & 0.621 \\
\hline & $329-344$ & FPNITNLCPFGEVFNA & 16 & 0.6058 \\
\hline & $245-260$ & HRSYLTPGDSSSGWTA & 16 & 0.6017 \\
\hline & $280-295$ & NENGTITDAVDCALDP & 16 & 0.5804 \\
\hline & $49-64$ & HSTQDLFLPFFSNVTW & 16 & 0.5305 \\
\hline & $492-507$ & LQSYGFQPTNGVGYQP & 16 & 0.5258 \\
\hline & $70-85$ & VSGTNGTKRFDNPVLP & 16 & 0.5162 \\
\hline & $236-251$ & TRFQTLLALHRSYLTP & 16 & 0.5115 \\
\hline & $266-281$ & YVGYLQPRTFLLKYNE & 16 & 0.5108 \\
\hline & $594-609$ & GVSVITPGTNTSNQVA & 16 & 0.4651 \\
\hline & $320-335$ & VQPTESIVRFPNITNL & 16 & 0.4454 \\
\hline \multirow{9}{*}{$\begin{array}{c}\text { Bepipred } \\
\text { v2.0 }\end{array}$} & $179-190$ & LEGKQGNFKNLR & 12 & 1.1188 \\
\hline & $404-426$ & GDEVRQIAPGQTGKIADYNYKLP & 23 & 1.1017 \\
\hline & $14-34$ & QCVNLTTRTQLPPAYTNSFTR & 21 & 0.7594 \\
\hline & $56-81$ & LPFFSNVTWFHAIHVSGTNGTKRFDN & 26 & 0.6041 \\
\hline & $208-222$ & TPINLVRDLPQGFSA & 15 & 0.5531 \\
\hline & $141-160$ & LGVYYHKNNKSWMESEFRVY & 20 & 0.5308 \\
\hline & $249-261$ & LTPGDSSSGWTAG & 13 & 0.495 \\
\hline & $306-321$ & FTVEKGIYQTSNFRVQ & 16 & 0.4361 \\
\hline & $615-644$ & VNCTEVPVAIHADQLTPTWRVYSTGSNVFQ & 30 & 0.4259 \\
\hline
\end{tabular}


Table 2 (on next page)

Details of epitopes in the preliminary immunodominant fragments selected according to linear B-cell epitope prediction results. 


\begin{tabular}{|c|c|c|c|c|c|c|}
\hline \multirow{2}{*}{ Regions } & \multicolumn{3}{|c|}{ Epitope predicted by ABCpred } & \multicolumn{3}{|c|}{ Epitope predicted by Bepipred v2.0 } \\
\hline & Position & Sequence & Antigenicity & Position & Sequence & Antigenicity \\
\hline \multirow{2}{*}{$49-85$} & $49-64$ & HSTQDLFLPFFSNVTW & 0.5305 & \multirow{2}{*}{$56-81$} & LPFFSNVTWFHAIHV & \multirow{2}{*}{0.6041} \\
\hline & $70-85$ & VSGTNGTKRFDNPVLP & 0.5162 & & SGTNGTKRFDN & \\
\hline \multirow{11}{*}{$200-344$} & $200-215$ & YFKIYSKHTPINLVRD & 0.6570 & $208-222$ & TPINLVRDLPQGFSA & 0.5531 \\
\hline & $236-251$ & TREQTLLALHRSYLTP & 0.5115 & \multirow{5}{*}{$249-261$} & \multirow{5}{*}{ LTPGDSSSGWTAG } & \multirow{5}{*}{0.4950} \\
\hline & $245-260$ & HRSYLTPGDSSSGWTA & 0.6017 & & & \\
\hline & $257-272$ & GWTAGAAAYYVGYLQP & 0.6210 & & & \\
\hline & $266-281$ & YVGYLQPRTFLLKYNE & 0.5108 & & & \\
\hline & $280-295$ & NENGTITDAVDCALDP & 0.5804 & & & \\
\hline & $288-303$ & AVDCALDPLSETKCTL & 0.7905 & \multirow{5}{*}{$306-321$} & \multirow{5}{*}{$\begin{array}{c}\text { FTVEKGIYQTSNERV } \\
\mathrm{Q}\end{array}$} & \multirow{5}{*}{0.4361} \\
\hline & $307-322$ & TVEKGIYQTSNFRVQP & 0.6733 & & & \\
\hline & $320-335$ & VQPTESIVRFPNITNL & 0.4454 & & & \\
\hline & $329-344$ & FPNITNLCPFGEVFNA & 0.6058 & & & \\
\hline & $415-430$ & TGKIADYNYKLPDDFT & 0.9642 & & & \\
\hline \multirow{4}{*}{$583-663$} & $583-598$ & EILDITPCSFGGVSVI & 1.3971 & \multirow{4}{*}{$615-644$} & \multirow{4}{*}{$\begin{array}{l}\text { VNCTEVPVAIHADQL } \\
\text { TPTWRVYSTGSNVFQ }\end{array}$} & \multirow{4}{*}{0.4259} \\
\hline & $594-609$ & GVSVITPGTNTSNQVA & 0.4651 & & & \\
\hline & $604-619$ & TSNQVAVLYQDVNCTE & 0.7593 & & & \\
\hline & $648-663$ & GCLIGAEHVNNSYECD & 0.8480 & & & \\
\hline
\end{tabular}




\section{Table 3 (on next page)}

MHC-II and MHC-I binding epitopes predicted by TepiTool server with antigenicity score exceed threshold value 


\begin{tabular}{|c|c|c|c|c|c|c|c|c|}
\hline Type & Position & Sequence & Length & Allele & $\begin{array}{c}\text { Core } \\
\text { (smm-align) }\end{array}$ & $\begin{array}{c}\text { Core } \\
\text { (nn-align) }\end{array}$ & Percentile Rank & $\begin{array}{l}\text { Antigenicity } \\
\text { (cut off } \geq 0.4\end{array}$ \\
\hline \multirow{15}{*}{$\begin{array}{l}\text { MHC-II } \\
\text { binding }\end{array}$} & $538-552$ & CVNFNENGLTGTGVL & 15 & $\mathrm{H} 2-\mathrm{IAb}$ & FNENGLTGT & FNFNGLTGT & 8.55 & 1.3281 \\
\hline & $374-388$ & FSTFKCYGVSPTKLN & 15 & $\mathrm{H} 2-\mathrm{IAb}$ & EKCYGVSPT & YGVSPTKLN & 6.45 & 1.0042 \\
\hline & $199-213$ & GYFKIYSKHTPINLV & 15 & H2-Iab & KIYSKHTPI & YSKHTPINL & 6.9 & 0.9278 \\
\hline & $18-32$ & LTTRTQLPPAYTNSF & 15 & $\mathrm{H} 2-\mathrm{IAb}$ & TRTQLPPAY & TRTQLPPAY & 9.9 & 0.79 \\
\hline & $60-74$ & SNVTWEHAIHVSGTN & 15 & $\mathrm{H} 2-\mathrm{IAb}$ & VTWEHAIHV & TWFHAIHVS & 9.1 & 0.7044 \\
\hline & $263-277$ & AAYYVGYLQPRTFLL & 15 & $\mathrm{H} 2-\mathrm{IAb}$ & VGYLQPRTF & VGYLQPRTF & 8.75 & 0.6073 \\
\hline & $592-606$ & FGGVSVITPGTNTSN & 15 & $\mathrm{H} 2-\mathrm{IAb}$ & VITPGTNTS & VSVITPGTN & 6 & 0.5825 \\
\hline & $238-252$ & FQTLLALHRSYLTPG & 15 & H2-IEd & TLLALHRSY & TLLALHRSY & 9.85 & 0.5789 \\
\hline & $345-359$ & TRFASVYAWNRKRIS & 15 & $\mathrm{H} 2-\mathrm{IAb}$ & EASVYAWNR & YAWNRKRIS & 7.45 & 0.4963 \\
\hline & $215-229$ & DLPQGFSALEPLVDL & 15 & $\mathrm{H} 2-\mathrm{IAb}$ & FSALEPLVD & FSALEPLVD & 6.05 & 0.4812 \\
\hline & $140-154$ & FLGVYYHKNNKSWME & 15 & H2-IEd & GVYYHKNNK & YYHKNNKSW & 6.4 & 0.4793 \\
\hline & $512-526$ & VLSEELLHAPATVCG & 15 & $\mathrm{H} 2-\mathrm{IAb}$ & FELLHAPAT & FELLHAPAT & 2.9 & 0.4784 \\
\hline & $87-101$ & NDGVYFASTEKSNII & 15 & H2-Iab & YFASTEKSN & VYFASTEKS & 6.85 & 0.4277 \\
\hline & $52-66$ & QDLFLPFFSNVTWFH & 15 & $\mathrm{H} 2-\mathrm{IAb}$ & FLPFFSNVT & FLPFFSNVT & 2.95 & 0.4159 \\
\hline & $233-247$ & INITRFQTLLALHRS & 15 & H2-IAd & ITRFQTLLA & ITRFQTLLA & 1.9 & 0.4118 \\
\hline \multirow{21}{*}{$\begin{array}{l}\text { MHC-I } \\
\text { binding }\end{array}$} & $643-651$ & FQTRAGCLI & 9 & $\mathrm{H}-2-\mathrm{Kk}$ & & & 0.6 & 1.7332 \\
\hline & $612-620$ & YQDVNCTEV & 9 & $\mathrm{H}-2-\mathrm{Db}$ & & & 0.4 & 1.6172 \\
\hline & $539-547$ & VNFNFNGLT & 9 & $\mathrm{H}-2-\mathrm{Kb}$ & & & 0.47 & 1.5069 \\
\hline & $503-511$ & VGYQPYRVV & 9 & $\mathrm{H}-2-\mathrm{Kb}$ & & & 0.47 & 1.4383 \\
\hline & $379-387$ & CYGVSPTKL & 9 & $\mathrm{H}-2-\mathrm{Kd}$ & & & 0.3 & 1.4263 \\
\hline & $16-24$ & VNLTTRTQL & 9 & $\mathrm{H}-2-\mathrm{Kb}$ & & & 0.86 & 1.3468 \\
\hline & $510-518$ & VVVLSFELL & 9 & $\mathrm{H}-2-\mathrm{Kb}$ & & & 0.43 & 1.0909 \\
\hline & $202-210$ & KIYSKHTPI & 9 & $\mathrm{H}-2-\mathrm{Kb}$ & & & 0.27 & 0.7455 \\
\hline & $168-176$ & FEYVSQPEL & 9 & $\mathrm{H}-2-\mathrm{Kk}$ & & & 0.5 & 0.6324 \\
\hline & $268-276$ & GYLQPRTFL & 9 & $\mathrm{H}-2-\mathrm{Kd}$ & & & 0.2 & 0.6082 \\
\hline & $505-513$ & YQPYRVVVL & 9 & H-2-Dd & & & 0.3 & 0.5964 \\
\hline & $488-496$ & CYFPLQSYG & 9 & $\mathrm{H}-2-\mathrm{Kd}$ & & & 0.64 & 0.578 \\
\hline & $215-223$ & DLPQGFSAL & 9 & H-2-Dd & & & 0.69 & 0.5622 \\
\hline & $342-350$ & FNATRFASV & 9 & $\mathrm{H}-2-\mathrm{Kb}$ & & & 0.56 & 0.5609 \\
\hline & $84-92$ & LPFNDGVYF & 9 & H-2-Ld & & & 0.21 & 0.5593 \\
\hline & $484-492$ & EGFNCYFPL & 9 & $\mathrm{H}-2-\mathrm{Kb}$ & & & 0.84 & 0.5453 \\
\hline & $62-70$ & VTWFHAIHV & 9 & $\mathrm{H}-2-\mathrm{Kb}$ & & & 0.61 & 0.5426 \\
\hline & $489-497$ & YFPLQSYGF & 9 & H-2-Dd & & & 0.8 & 0.5107 \\
\hline & $350-358$ & VYAWNRKRI & 9 & $\mathrm{H}-2-\mathrm{Kd}$ & & & 0.7 & 0.5003 \\
\hline & $60-68$ & SNVTWFHAI & 9 & $\mathrm{H}-2-\mathrm{Kb}$ & & & 0.82 & 0.4892 \\
\hline & $262-270$ & AAAYYVGYL & 9 & $\mathrm{H}-2-\mathrm{Kb}$ & & & 0.98 & 0.4605 \\
\hline
\end{tabular}


Table 4 (on next page)

Details of candidate immunodominant fragments adjusted according to the MHC-II binding T-cell epitopes prediction results. 
1

\begin{tabular}{|c|c|c|c|c|c|c|c|}
\hline \multirow{2}{*}{ Regions } & \multicolumn{4}{|c|}{ Linear B-cell epitopes } & \multicolumn{3}{|c|}{ MHC-II binding epitopes } \\
\hline & Tools & Position & Sequence & Antigenicity & Position & Sequence & Antigenicity \\
\hline $14-34$ & $\begin{array}{l}\text { Bepipred } \\
\text { v2.0 }\end{array}$ & $14-34$ & $\begin{array}{c}\text { QCVNLTTRTQLPPAYTN } \\
\text { SFTR }\end{array}$ & 0.7594 & $18-32$ & LTTRTQLPPAYTNSF & 0.7900 \\
\hline \multirow{3}{*}{$49-101$} & $\begin{array}{l}\text { Bepipred } \\
\text { v2.0 }\end{array}$ & $56-81$ & $\begin{array}{c}\text { LPFFSNVTWFHAIHVSG } \\
\text { TNGTKRFDN }\end{array}$ & 0.6041 & $52-66$ & QDLFLPFFSNVTWFH & 0.4159 \\
\hline & ABCpred & $49-64$ & HSTQDLFLPFFSNVTW & 0.5305 & $60-74$ & SNVTWFHAIHVSGTN & 0.7044 \\
\hline & ABCpred & $70-85$ & VSGTNGTKRFDNPVLP & 0.5162 & $87-101$ & NDGVYFASTEKSNII & 0.4277 \\
\hline \multirow{13}{*}{$199-359$} & \multirow{3}{*}{$\begin{array}{c}\text { Bepipred } \\
\text { v2.0 }\end{array}$} & $208-222$ & TPINLVRDLPQGFSA & 0.5531 & \multirow{4}{*}{$199-213$} & \multirow{4}{*}{ GYFKIYSKHTPINLV } & \multirow{4}{*}{0.9278} \\
\hline & & $249-261$ & LTPGDSSSGWTAG & 0.4950 & & & \\
\hline & & $306-321$ & FTVEKGIYQTSNFRVQ & 0.4361 & & & \\
\hline & \multirow{10}{*}{ ABCpred } & $200-215$ & YFKIYSKHTPINLVRD & 0.6570 & & & \\
\hline & & $236-251$ & TRFQTLLALHRSYLTP & 0.5115 & \multirow{2}{*}{$215-229$} & \multirow{2}{*}{ DLPQGFSALEPLVDL } & \multirow{2}{*}{0.4812} \\
\hline & & $245-260$ & HRSYLTPGDSSSGWTA & 0.6017 & & & \\
\hline & & $257-272$ & GWTAGAAAYYVGYLQP & 0.6210 & \multirow{2}{*}{$233-247$} & \multirow{2}{*}{ INITRFQTLLALHRS } & \multirow{2}{*}{0.4118} \\
\hline & & $266-281$ & YVGYLQPRTFLLKYNE & 0.5108 & & & \\
\hline & & $280-295$ & NENGTITDAVDCALDP & 0.5804 & \multirow{2}{*}{$238-252$} & \multirow{2}{*}{ FQTLLALHRSYLTPG } & \multirow{2}{*}{0.5789} \\
\hline & & $288-303$ & AVDCALDPLSETKCTL & 0.7905 & & & \\
\hline & & $307-322$ & TVEKGIYQTSNFRVQP & 0.6733 & \multirow[b]{2}{*}{$263-277$} & \multirow[b]{2}{*}{ AAYYVGYLQPRTFLL } & \multirow[b]{2}{*}{0.6073} \\
\hline & & $320-335$ & VQPTESIVRFPNITNL & 0.4454 & & & \\
\hline & & $329-344$ & FPNITNLCPFGEVFNA & 0.6058 & $345-359$ & TRFASVYAWNRKRIS & 0.4963 \\
\hline \multirow{3}{*}{$583-620$} & \multirow{3}{*}{ ABCpred } & $583-598$ & EILDITPCSFGGVSVI & 1.3971 & \multirow{3}{*}{$592-606$} & \multirow{3}{*}{ FGGVSVITPGTNTSN } & \multirow{3}{*}{0.5825} \\
\hline & & $594-609$ & GVSVITPGTNTSNQVA & 0.4651 & & & \\
\hline & & $604-619$ & TSNQVAVLYQDVNCTE & 0.7593 & & & \\
\hline
\end{tabular}




\section{Table 5 (on next page)}

Significant features of the selected immunodominant fragments.

The sequences marked as bold and italic in the table represent amino acids with hydrophilicity and surface accessibility respectively 


\begin{tabular}{|c|c|c|c|}
\hline Fragments & Spike $_{56-94}$ & Spike $_{199-264}$ & Spike $_{577-612}$ \\
\hline Length(aa) & 39 & 66 & 36 \\
\hline \multirow{3}{*}{ Sequence } & LPFFSNVTWFHAIHVS & GYFKIYSKHTPINLVRDLPQGFSALEPLVD & RDPQTLEILDITPCSFG \\
\hline & GTNGTKRFDNPVLPF & LPIGINITRFQTLLALHRSYLTPGDSSSGW & GVSVITPGTNTSNQVA \\
\hline & NDGVYFAS & TAGAAA & VLY \\
\hline Antigenicity & 0.4590 & 0.5774 & 0.9127 \\
\hline Domain & S1(NTD) & $\mathrm{S} 1(\mathrm{NTD})$ & S1 \\
\hline \multirow{3}{*}{$\begin{array}{c}\text { Hydrophilicity } \\
\text { fragments }\end{array}$} & LPFFSNVTWFHAIH $\boldsymbol{V S}$ & GYF KIYSKHTPINLVRDLPQGFSALEPLVD & RDPQTLEILDITPCSFG \\
\hline & GTNGTKRFDNPVLPF & LPIGINITRFQTLLALHRSYLTPGDSSSGWT & GVSVITPGTNTSNQVA \\
\hline & NDGVYFAS & AGAAA & VLY \\
\hline \multirow{3}{*}{$\begin{array}{c}\text { Surface Accessibi } \\
\text { lity fragments }\end{array}$} & LPFFSNVTWFHAIHV & GYFKIYSKHTPINLVRDLPQGFSALEPLV & $R D P Q T L E I L D I T P C S F G$ \\
\hline & SGTNGTKRFDNPVLPF & DLPIGINITRFQTLLALHRSYLTPGDSSSG & GVSVITPGTNTSNQVA \\
\hline & NDGVYFAS & WTAGAAA & VLY \\
\hline Toxicity & Non-toxin & Non-toxin & Non-toxin \\
\hline Allergenicity & non-allergen & non-allergen & probable allergen \\
\hline
\end{tabular}

1 
Table 6(on next page)

The structure and antigenicity of final recombinant peptides 


\begin{tabular}{cc}
\hline Final construct & PAN DR $+(\text { GGGGS })_{2}+$ Spike $_{56-94}+\left(\right.$ GGGGS $_{3}+$ Spike $_{199-264}+\left(\right.$ GGGGS $_{3}+$ Spike $_{577-612}$ \\
\hline Aequence & GGGGSGYFKIYSKHTPINLVRDLPQGFSALEPLVDLPIGINITRFQTLLALHRSYLTPGDSSSGWTAGAAAG \\
& GGGSGGGGSGGGGSRDPQTLEILDITPCSFGGVSVITPGTNTSNQVAVLY \\
\hline Antigenicity & 0.5690 \\
\hline
\end{tabular}

1 